\title{
A Web-Based Tool for Product Ideas Screening and Lifestyle Analysis
}

\author{
Shih-Yen Huang \\ Department of Industrial Design, Huafan University, New Taipei City 22301, Taiwan \\ Correspondence should be addressed to Shih-Yen Huang; mark2a9239@gmail.com
}

Received 5 June 2014; Accepted 31 July 2014; Published 27 August 2014

Academic Editor: Teen-Hang Meen

Copyright ( 2014 Shih-Yen Huang. This is an open access article distributed under the Creative Commons Attribution License, which permits unrestricted use, distribution, and reproduction in any medium, provided the original work is properly cited.

\begin{abstract}
In the era of consumerism nowadays, market needs are the key factors that trigger the commercial opportunity of a product. In addition to the functional and aesthetic requirements of products, designers need to consider user's demands and preferences in product design and development. In this study, a web-based tool was developed by the combination of life style questionnaire and image scale survey. The data obtained from the survey served as references for new product design and marketing promotion. In our study, proposals for public outdoor facilities with local cultural features were developed as an example to illustrate the application of the web-based tool. Through such a web-based tool, demographic data, attitudes in life style, and suitability of design proposals were collected in the form of coordinate and diagrams. In this way, a suitable design proposal for the community was selected and the life style characteristics of the target user group were specified for further design and development of the public facility.
\end{abstract}

\section{Introduction}

1.1. Background. Many factors are interwoven in the decision-making of a new product design and development procedure. According to Baxter, market pull is stronger than technology push. In the consumerism era, consumers' preferences and feelings should be taken into consideration. Furthermore, because of the diversity of consumer behaviors in the market, different life styles of user groups may result in the market diversification [1]. From this viewpoint, designers need to consider user's needs and preferences in product design and development.

With the development of web technique, many scholars have constructed analytical tools for product form through websites. In this way, designers can grasp the consumer's feelings of product images so as to work out products that meet the requirements of consumers [2]. The image data survey system by Ikudame and Harada [3] and multidimensional scaling questionnaire by Tu [4] are two examples. However, most of these studies focus upon the analysis of external appearance of product from the viewpoints of designers. The literature regarding product preferences of different consumer groups and life styles is rare. Therefore, in this study, consumers' attitudes and their feelings toward product design were integrated for the evaluation of new product proposals. The storage, retrieval, and calculation of the data were made possible through the website survey and database. From the interactive interface in the web-based image evaluation tool, the subjects process their perceptions and cognition toward different product samples on the 2-dimensional analytical scale. Moreover, the researcher can obtain the personal data and opinions of life style survey in tables and diagrams, making it convenient for further analysis and strategy drafting.

In this study, the web-based tool and life style studies were first discussed in Introduction section. Then in Methodology, the theoretical basis and the interface design of the web-based tool were described. The A.I.O. (activities, interests, opinions) questionnaire and proposals for outdoor facilities were also covered in this section. In the Results and Discussion section, the selection of design ideas and the establishment of promotional strategy based upon the life style of consumer groups were explained. The characteristics of target user groups were specified to promote the development of new public outdoor facilities. 
1.2. The Development of the Web-Based Image Evaluation Tool. In the 1970s, Nagamagi devoted himself to Kansei Engineering, a new technique in which consumer's feelings and image perceptions toward products were transformed into product design elements. These design elements are product properties that the consumers really want. According to Nagamagi, the purpose of Kansei Engineering is to reach a physically and psychologically harmonic situation while the consumer is using a product. Furthermore, he offered a new concept to conduct the consumer survey through computers [5]. In his model, the design-oriented database is built to help designers take consumers' emotional needs into control in order to design products that meet the requirements in the market.

Since then, many researchers have done studies under the name of Kansei Engineering. For example, Chuang and Kao made a study on product images and claimed that through various products from elements such as lines, colors, texture, and structure and context meaning from the social environment, the communication between product and users comes into being. The messages transmitted from products are taken from the viewpoints of consumers [6]. Furthermore, images are endowed in the product form which the designers work out according to user's needs, feelings, and thoughts. Hsu et al. made a study on the differences of designers and users in product image perceptions and found that there existed differences to some extent between designers and users [2]. Chuang et al. investigated the perceptual factors underlying user preferences toward product form and proposed an algorithm to generate suitable ideas for new product form of mobile phones [7]. Chuang and Ma studied the relationships between design elements and product images and worked out design specifications for product form design in electronic products [8]. From a case study of car design, Chang et al. explored the expression modes used by consumers in conveying desire for product form [9]. In these studies, image data were collected from semantic differential method (SD) and further analyzed through varying statistical analytical tools [10]. However, it takes professional training to process these statistical analyzes, they are not often applied in the industry and design field. In enterprises and design houses, image scale has often been used for product form analysis. The image scale was proposed by Nippon Color and Design Research Institute (NCD) in the 1980s [11]. At first, it used the concepts of color theory and psychology to create the 2-dimensional image analytical diagram. Along the axes, $X$ axis represents cool and warm tones while $Y$ axis represents soft and hard degrees of the product image samples. However, the title of image words along the axes can be changed according to the needs of the design project. On the scale, the user's feelings of the stimulus, the photographic images, are visualized and presented in a systematic diagram to keep the design team on the right track. Such an image scale is widely used in color planning and product form analyses in design houses all over the world.

The widespread of the Internet helps promote the image scale analysis. Nowadays, the sharing of many design concepts, the integration of design and manufacturing, and the marketing survey of products and consumer behaviors and attitudes have been incorporated with the website. With the arrival of the trend of sharing design ideas in the Internet, a collaborative environment has been built through WWW. In this way, designers in different places can work together on a design project. For example, Roy and Kodkani integrated database and WWW and made it possible for designers in a team to save and retrieve survey data through a web-based product conceptualization tool [12]. Moreover, Huang et al. pointed out that designers could be integrated for design routines and decision-making tasks in a web based environment [13].

With the popularity of the Internet, web technique has been progressively used to improve the shortages in the traditional product image survey. In a study of the production of multidimensional scaling questionnaire, Tu adopted the World Wide Web platform to construct the survey. From the WWW platform, it is possible for designers to generate website questionnaire and conduct the survey online and automatically collect the data they need [4]. In addition, in a study of visual image measurement, Ikudame and Harada proposed a survey system for image data by Hypercard 2.2. Such a system can be set to compare product images according to some specific images and gather statistical data like the subject's basic profile and the raw data of the perception evaluation [3]. However, after the semantic evaluation, the locations of the image sample could not be adjusted.

The above researchers conducted product image analyzes through web technique to help designers grasp consumers' preferences toward product styling images. However, consumer's life style data are not covered in these analytical systems. To cope with this problem, product idea screening and market promotion were integrated in the web-based tool.

1.3. Culture and Design. In the book "Primitive Cultures," Taylor gave a classic definition of culture. From the viewpoint of anthropology, the so-called culture or civilization is a complex entity, including knowledge, belief, arts, morals, laws, customs, and other abilities which members of a society have acquired [14]. In this definition, culture is defined as the result of evolutionary process in the society by interactions, which include the conception in spirit, norms for life and society, and the interaction of objects.

Wuthnow pointed out that cultural factors emerge in all layers of our life in varying ways, which at the same time endow meanings and possibilities to culture [15]. Therefore, culture can be defined as the symbolic expressions of human behaviors. Moreover, from the spatial perspective of culture, Leong and Clark developed a framework for studying cultural objects distinguished by three special levels: the outer "physical or tangible" level, the mid "behavioral" level where rites and rules of semantics are involved, and the inner "intangible" level that displays human ideology and abstract spirits [16].

Lin (2005) claimed that the purpose of design is to improve the quality of human life and promote the cultural level of our society [17]. In light of this, designers need to take hold of the cultural pace in the society and respond in their design. As a result, the cultural industry can promote the recognition of local culture. Therefore, from the image transformation of cultural products, arts and culture can dominate 
the identification of historic memories and local characteristics, another way that emphasizes the development of local industry.

In this study, the middle level in the spatial perspective of culture is explored. Because the residents in Pearl Community have special feelings toward rice straw and there is a rice straw museum in the community to promote the local characteristics for tourism. Public outdoor facilities were chosen as an example for the development of the web-based tool for product idea screening and promotion. Taking local culture into consideration, the images of straw bunch and haystack were transformed for the design and development of public outdoor facilities.

1.4. Life Style Studies. Life style studies have been widely applied in marketing where meanings of different life styles are explored from different aspects. Lazer considered life style as a system concept: it represents features for the whole society or the life for a specific population [18]. Berman and Evans pointed out that the demographic and life style variables are factors that mainly affect consumers' decisions [19]. Engel et al. indicated that the life styles of individuals would be deeply influenced by the social environment. In addition, differences in personal characters and sense of value would also cast a big impact upon a person's life style, resulting in varying individual decision-making and general profiting seeking behavior or even bringing forth some special behavioral patterns [20]. As a result, it is very possible that such life style studies can be medium for product design and promotion. The present study of the web-based tool and the life style of consumers are mainly based upon this assumption.

In the survey of life style, Wells and Tigert developed the A.I.O. attitude scale upon which many studies of life style were based [21]. In addition, Plummer included the demographic variables and proposed activities, interests, opinions, and demographic variables for fundamental dimensions of life style. In this study, appropriate A.I.O. variables were chosen from these life style dimensions to measure the activity, interest, and opinions of the participants [22].

It is a trend in marketing to conduct market segmentation through life style study. In order to draft a proper market promotion strategy, researchers should take the characteristics of the target market into control. And among various differentiation variables, life style variables can fully reflect the heterogeneousness of the consumers. Furthermore, preferences and promotional strategies for specific target user groups can be identified.

1.5. Aim of the Study. There is quite a lot of literatures regarding consumers in culture, geography, and the like A.I.O. population statistics. However, studies adopting a cross-analysis for market segmentation through product image analysis from the website are rare. At the present study, common life style items such as jobs, leisure activities, political preferences, and personal interests were covered in addition to the image evaluation along the axes of attractiveness and cultural creativity. The promotional strategies for proposals of public outdoor facilities were developed based on the everyday habits and inclinations of the target user group and activities they like to participate.

\section{Methodology}

In this section, the quantitative model was described. More importantly, details of the idea evaluation and life style survey were explained. In this study, the web-based tool was used to select design proposals preferred by the target user group. Furthermore, a life style survey was conducted to explore the characteristics of the target user group so as to develop a proper promotional strategy for the cultural product design. The study was divided into three stages. In Stage 1, the life style questionnaire was drafted and added to the web-based tool. Local residents were interviewed for the exploration of design properties of the cultural product in Pearl Community, YiLan County, Taiwan. Based upon Stage 1, ideas for public outdoor facility were developed at Stage 2. The subjects' basic profile, life style data, and their preferences towards proposals of public outdoor facility were collected through the website. At Stage 3, data obtained from Stage 2 were collected for statistical analyzes. Product idea most suitable for the target user group was selected. Finally, the promotional strategy for public outdoor facility in Pearl Community was chosen from the feature analysis of life style of the target user group.

2.1. The Quantitative Model of the Web-Based Analytical Tool. Though the image scale is frequently used by the industry and design houses, it is a problem to extend few designers' subjective data to the major consumers. To cope with such a problem, Huang and Lin developed a web-based tool for the collection of image data of product form. In their model, coordinate of the positions subjects which places the image sample on the image scale is obtained and the calculation of gravitation is automatically generated for the quantitative image database [23]. Besides, we can calculate the average coordination value of a product, $\left(x^{(n)}, y^{(n)}\right)$, through $n$ subjects' coordinates and weights to the same product by Formulae (1a) and (1b). If equal weights are assigned, $w_{i}=1$, $i=1,2,3, \ldots, n$, then Formulae (1a) and (1b) can be simplified to Formulae (2a) and (2b)

$$
\begin{aligned}
x^{(n)} & =\frac{\sum_{i=1}^{n} w_{i} x_{i}}{\sum_{i=1}^{n} w_{i}} \\
y^{(n)} & =\frac{\sum_{i=1}^{n} w_{i} y_{i}}{\sum_{i=1}^{n} w_{i}} \\
x^{(n)} & =\frac{1}{n} \sum_{i=1}^{n} x_{i} \\
y^{(n)} & =\frac{1}{n} \sum_{i=1}^{n} y_{i} .
\end{aligned}
$$

In this study, three ideas of public outdoor facilities were evaluated in the similar way by 370 subjects along the attractiveness and cultural creativity axes. 
TABLE 1: The content of the AIO questionnaire survey.

\begin{tabular}{lc}
\hline Activities & Category briefing \\
\hline (A2) I usually go shopping and see movies and shows on holidays. & Outdoor activity \\
(A3) I will compare the prices in shopping. & Picky in shopping \\
(A5) I will spare time doing exercises every day. & Regular exercises \\
(A11) I make it a rule to meet friends. & Regular meeting \\
(A13) I lead a regular life routine. & Regular life \\
\hline Interests & Category briefing \\
\hline (I1) I enjoy the charitable activity. & Active in public welfare \\
(I4) I like to stay with my family or roommate after work. & Household life \\
(I6) I will pay attention to the fashion trends through magazines or media. & Fashion sensitive \\
(I7) I enjoy getting things done alone. & Independent worker \\
(I10) I hope to get job affirmation and appreciation from my superior. & Job affirmation \\
\hline Opinions & Category briefing \\
\hline (O8) I think leisure is more important than work. & Leisure first \\
(O9) I think brand is closely related to the product quality. & Brand loyalty \\
(O12) I care about personal appearance, dress, and adornment. & Appearance aware \\
(O14) I am not interested in politics. & Political indifference \\
(O15) I think the current social situation will affect my life routine. & Social anxiety \\
\hline
\end{tabular}

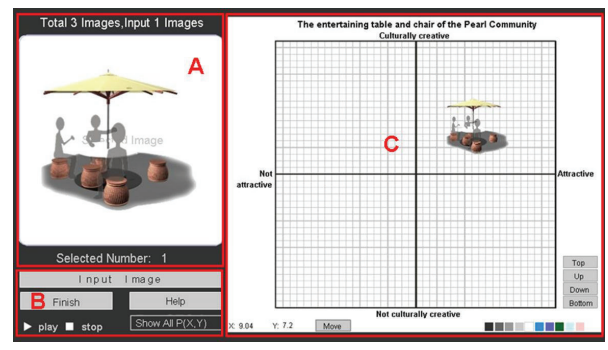

Figure 1: The test area in the web-based tool.

2.2. The Operational Interface of the Design Decision Tool. There is quite a lot of literatures regarding consumers in culture, geography, and the like A.I.O. population statistics. However, studies adopting a cross-analysis for market segmentation through product image analysis from the website are rare. At the present study, common life style items such as jobs, leisure activities, political preferences, and personal interests were covered in addition to the image evaluation along the axes of attractiveness and cultural creativity. The promotional strategies for proposals of public outdoor facilities were developed based on the everyday habits and inclinations of the target user group and activities they like to participate.

Table 1 lists the content of the A.I.O. questionnaire survey. There were 15 questions for activities, interests, and opinions in the life style survey, each of which consisted of five questions. Item numbers of the questions are shown on the left side and the right side shows the briefing category of the question described in the text.

When the subjects enter the test page (Figure 1), they can see three areas: the image area (Area A) on the upper left part displays the static or dynamic graphics of the product sample; the lower left part is the control area (Area B) in which the subject can input another image sample and play or stop the dynamic graphics; the right area serves as an image scale (Area C) where the subject can drag the input image from the central point $(0,0)$ to a proper position. A click on the input image button will repeat the evaluation process until all image samples are evaluated. A click on the finish button brings an end to the image evaluation. The image words used along the axis reflected the local features of Pearl Community at YiLan County, Taiwan. They were obtained from the website survey and face-to-face interviews of staff members in the community development society.

In this study, the image words required by the Pearl Community Development Society were adopted. Based upon the tourism requirements and local rice culture, the $X$ axis represents the attractiveness of the product ideas while $Y$ axis means the degree of cultural creativity of the public outdoor entertaining facilities. The product idea screening was processed on the basis of product form attractiveness and cultural creativity.

\subsection{Idea Development of the Public Outdoor Entertaining} Facilities. A design project of public outdoor facilities for the development of Pearl Community and local lodges at Yi-Lan County was used as a case for the web-based tool. The ideas included a table, a sun shade, and three or four chairs. They reflected the local features of Pearl Community such as the rice straw bunch, haystack, and the like agricultural symbols as shown in Figures 2(a) and 2(b).

Figure 3 lists three proposals that indicate the haystack feature and local environment.

Idea 1 has the following features.

(1) The sunshade features the rice straw bunch and extends to the chair design. When it is closed, an image of the rice straw bunch can be seen. 


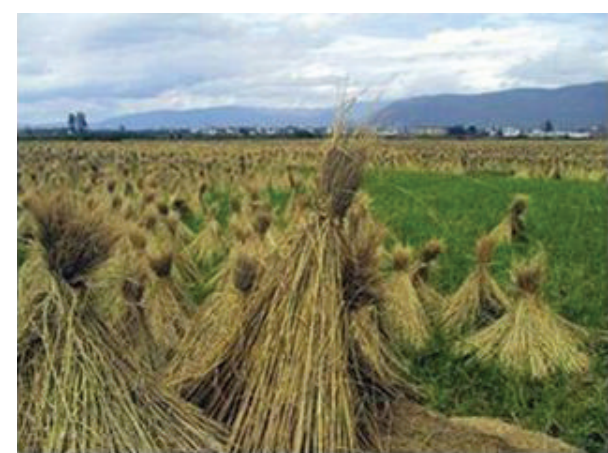

(a) Rice straw bunch

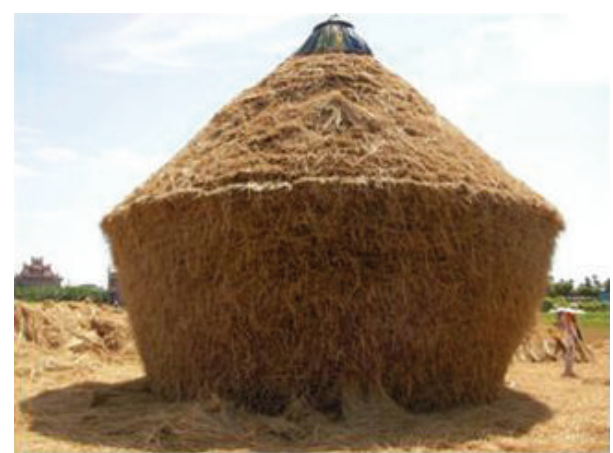

(b) Haystack

Figure 2: Local cultural feature of Pearl Community at Yi-Lan County, Taiwan.

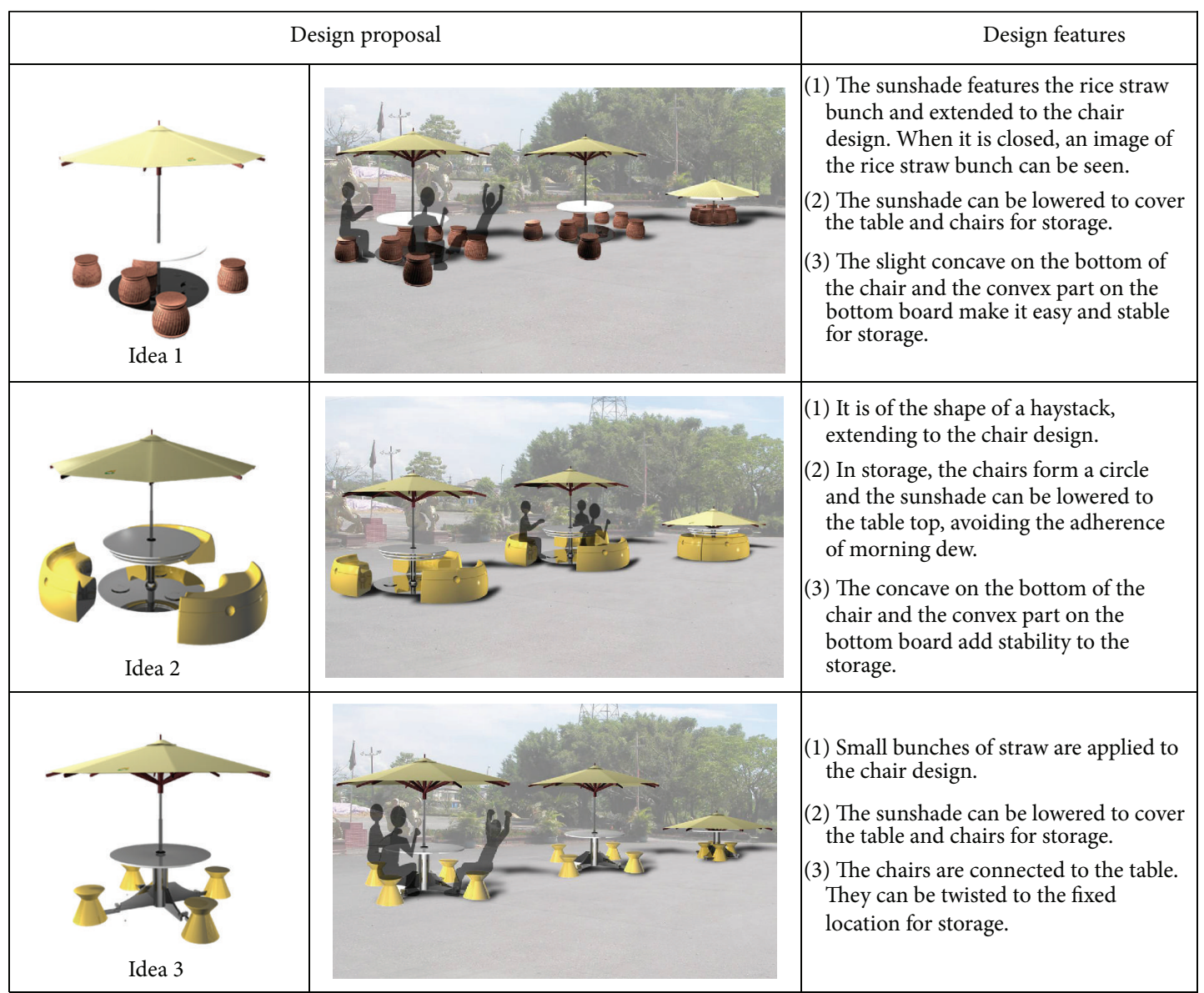

FIGURE 3: Features of three design proposals for public outdoor facility.

(2) The sunshade can be lowered to cover the table and chairs for storage.

(3) The slight concave on the bottom of the chair and the convex part on the bottom board make it easy and stable for storage.

Idea 2 has the following features.

(1) It is of the shape of a haystack, extending to the chair design.
(2) In storage, the chairs form a circle and the sunshade can be lowered to the table top, avoiding the adherence of morning dew.

(3) The concave on the bottom of the chair and the convex part on the bottom board add stability to the storage.

Idea 3 has the following features.

(1) It is of the shape of a haystack, extending to the chair design. 


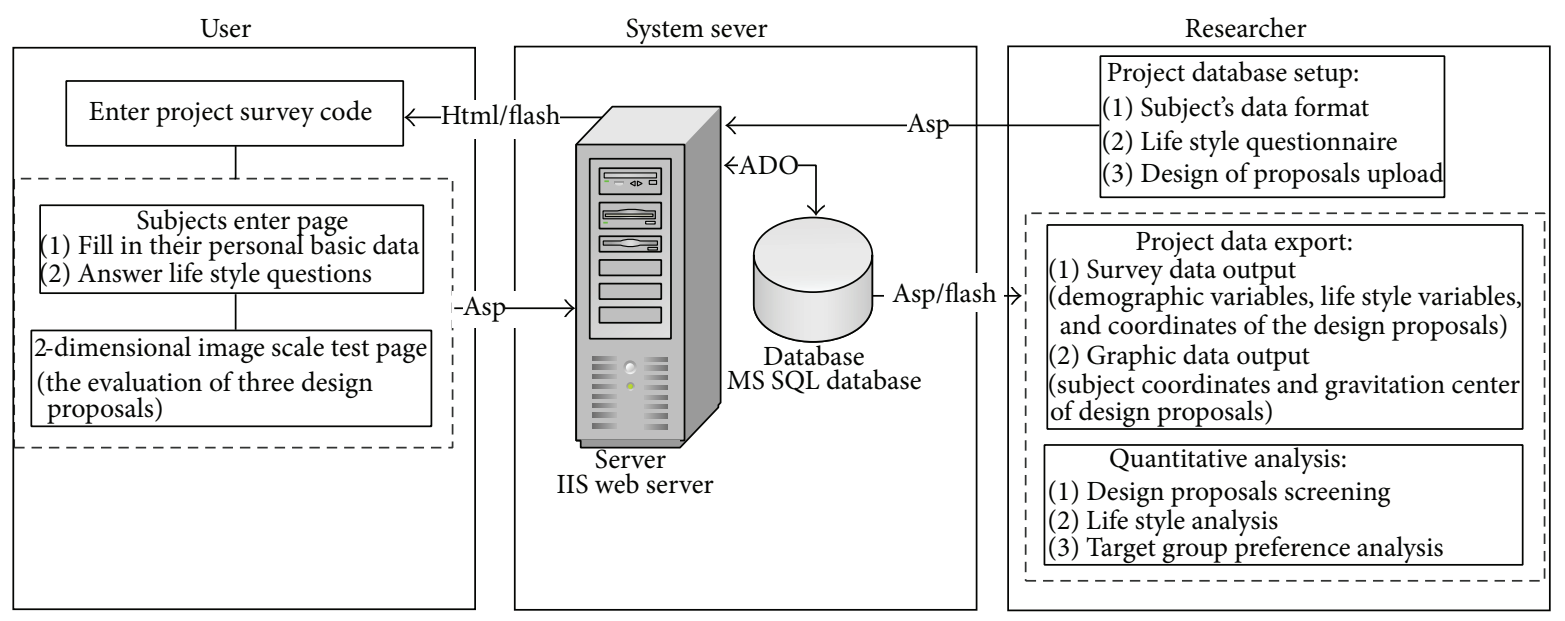

FIgURE 4: The framework for the interactive web-based analytic system.

(2) In storage, the chairs form a circle and the sunshade can be lowered to the table top, avoiding the adherence of morning dew.

(3) The concave on the bottom of the chair and the convex part on the bottom board add stability to the storage.

2.4. Procedure of the Idea Screening and Life Style Survey. Considering the operation system of the web-based tool in the design industry, the interface of the design decision tool had been improved by combining Adobe FLASH, ASP (active server pages), HTML, and database techniques to extend the functions of the web-based tool. This makes it easier for the survey on the Internet. With the system, it is possible to gather the subject's opinions regarding the product ideas and their life styles.

With the help from Pearl Community Development Society, three design proposals for the public outdoor facility were evaluated by the target user groups. The subjects were divided into three groups: community development staff, local residents, and tourists. The reason for the assessment was to examine whether the community development staff and local residents held the same points of view regarding the fitness of allocating the public facility in Pearl Community. For the tourist group, it was aimed at double-checking whether the design proposals were culturally creative and fitted the local environment of Pearl Community as follows: test place: Office of Pearl Community Development Society; test time: day time on the weekend; subjects: 370 subjects were collected from the survey, including staff members and volunteers in the community development society, local residents, and tourists; experimental materials: SWF dynamic images of three proposals of public outdoor facility; and evaluation procedures are as follows. (1) Through the help of Pearl Community Development Society, a briefing of the cultural and environmental features was made to the tourists. (2) The test was conducted by individuals online. Subjects would not be interfered by others during the test and they could do the test on their own pace. (3) Before entering the test page of the web-based tool, a tutorial was offered to explain its purpose and how to use the web-based tool. (4) Subjects entered a page to fill in their personal basic data and answer life style questions. (5) Entering the test page of the web-based tool for the evaluation of three design proposals of public outdoor facility, subjects could choose different views of image or the short animation where different views of design proposals were played. After they understood the features and differences among three proposals, they were asked to remove the images onto proper locations along $X$ and $Y$ axes. (6) After the evaluation was done, personal data, attitudes to life style questions, and coordination of their evaluation were saved for further statistical analyzes.

After the subject finishes filling in the personal data and locating product sample images onto the image scale, the personal data, life style A.I.O. survey, and coordinates of the product samples will be stored in the server by the ASP software. For researchers and designers, these data can be downloaded in tables or graphics for further statistical analyzes. Figure 4 illustrates the framework for the interactive webbased tool. With the data of demographic variables, life style variables, and coordinates of the design proposals on the web-based tool, a proper design idea was selected and then a promotional strategy was adopted from life style analysis.

\section{Results and Discussion}

3.1. The Distribution Patterns of Design Proposals on the WebBased Tool. From the database in the web-based tool, subjects' data can be downloaded in Html or Excel format for further analysis. In this study, Cronbach's $\alpha$ was used to evaluate the reliability of the coordinates for three design proposals. The result of reliability examination revealed that Cronbach's $\alpha=0.871>0.7$, indicating that the data from the web-based tool was highly reliable for further analysis of idea screening. From the web-based tool, gravitation center for each user group could be calculated. Particularly, the system can show the distribution pattern either of the total subjects or of each subject.

Through the web-based tool, the distribution pattern for design proposals can be prompted immediately. Figure 5 
TABLE 2: The verification of hypotheses in the selection of design proposals.

\begin{tabular}{|c|c|c|c|}
\hline Tests & Research hypotheses & $P$ value & Test result \\
\hline Total test & $\mathrm{H}_{1}$ : the model is significant. & $<.0001^{*}$ & Significant \\
\hline Marginal test of attractiveness & $\begin{array}{l}\mathrm{H}_{1} \text { : the model of attractiveness is } \\
\text { significant. }\end{array}$ & $<.0001^{*}$ & Significant, \\
\hline Paired test of attractiveness & $\begin{array}{l}\mathrm{H}_{1} \text { : there exist significant differences in } \\
\text { attractiveness between every two ideas. }\end{array}$ & & See Table 3 \\
\hline Contrast test of attractiveness & $\begin{array}{l}\mathrm{H}_{1} \text { : there exist significant differences in } \\
\text { attractiveness between ideas. }\end{array}$ & $<.0001$ & Significant \\
\hline Marginal test of cultural creativity & $\begin{array}{l}\mathrm{H}_{1} \text { : the model of cultural creativity is } \\
\text { significant. }\end{array}$ & $<.0001^{*}$ & Significant, \\
\hline Paired test of cultural creativity & $\begin{array}{l}\mathrm{H}_{1} \text { : there exist significant differences in } \\
\text { cultural creativity between every two } \\
\text { ideas. }\end{array}$ & & See Table 3 \\
\hline Contrast test of cultural creativity & $\begin{array}{l}\mathrm{H}_{1} \text { : there exist significant differences in } \\
\text { cultural creativity between ideas. }\end{array}$ & $<.0001^{*}$ & Significant \\
\hline
\end{tabular}

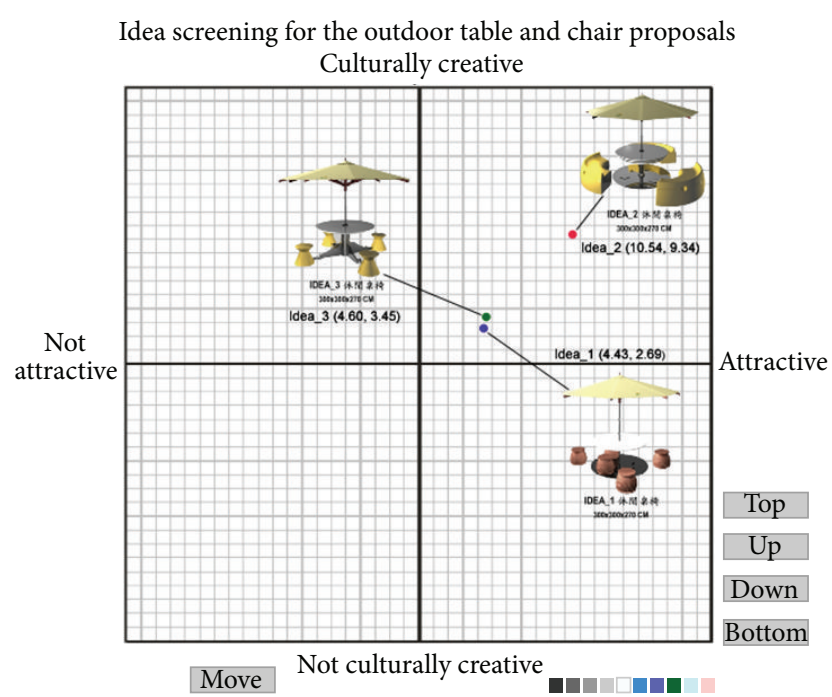

Figure 5: The final locations of three design proposals.

shows the final locations of three design proposals. Idea $1(4.43,2.69)$, Idea $2(10.54,9.34)$, and Idea $3(4.60,3.45)$ were located in first quadrant, meaning that the subjects considered them attractive and culturally creative for the image in Pearl Community. Because the coordinates of Idea 1 and Idea 3 were very close, they were partially overlapped in Figure 5.

Furthermore, different outputs of distribution pattern of design proposals for public outdoor facility can be chosen from the settings of user group profile in the column. The researcher can choose specific range from the variables like age, education, work experience, and life style group for special output diagrams while choose and calculate the group center (Figure 6).

The average center points and locations of each subject can be generated. Figure 7 shows locations of the evaluation of design proposal 2 of public outdoor facility, respectively.

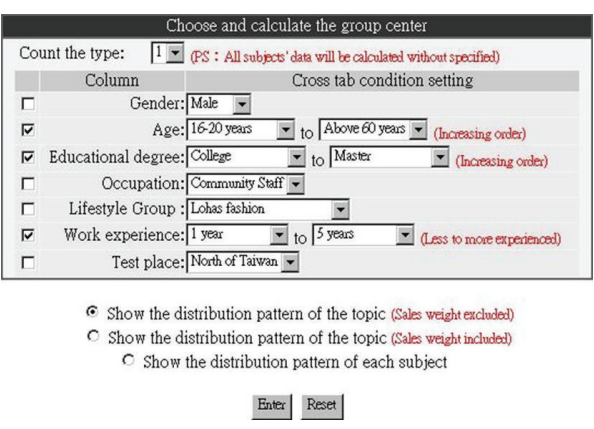

FIGURE 6: For target group choose and calculate the group center interface.

From the output tables and diagrams, it is clear that the researcher can control the status of the evaluation of the tested product samples through the prompted output interface in the web-based tool, from which the real-time data can be offered to designers and marketing personnel for idea screening.

3.2. The Comparison of Design Proposals. Through the output interface of the web-based tool, the demographic data of the subjects and the coordinates of the tested product samples can be obtained for further quantitative analysis. The degrees of subjects' preferences towards the product samples and the A.I.O. life style survey, proper ideas, and promotional strategy can be drafted.

In this study, a one-way MANOVA was conducted to examine whether there existed significant differences among three design proposals. The raw data for each design proposal was used to verify the research hypotheses and select the most appropriate idea. It was found that the Wilks' Lambda $P$ value $\leq 0.0001<0.05$, showing that there were significant differences among three design proposals of public outdoor facility. Table 2 lists the output data for different research hypotheses. It is clear that there were significant differences among these design proposals in terms of attractiveness and 
TABle 3: The pairwise comparison of three design proposals along $X$ axis (attractiveness) and $Y$ axis (cultural creativity).

\begin{tabular}{|c|c|c|c|c|c|}
\hline IDEA & $X$ LSMEAN & Group & 1 & 2 & 3 \\
\hline 1 & 4.43 & 1 & & $<.0001$ & .7470 \\
\hline 2 & 10.54 & 2 & $<.0001^{*}$ & & $<.0001$ \\
\hline 3 & 4.60 & 3 & .7470 & $<.0001^{*}$ & \\
\hline IDEA & $Y$ LSMEAN & Group & 1 & 2 & 3 \\
\hline 1 & 2.69 & 1 & & $<.0001$ & .1471 \\
\hline 2 & 9.34 & 2 & $<.0001^{*}$ & & $<.0001$ \\
\hline 3 & 3.45 & 3 & .1471 & $<.0001^{*}$ & \\
\hline
\end{tabular}

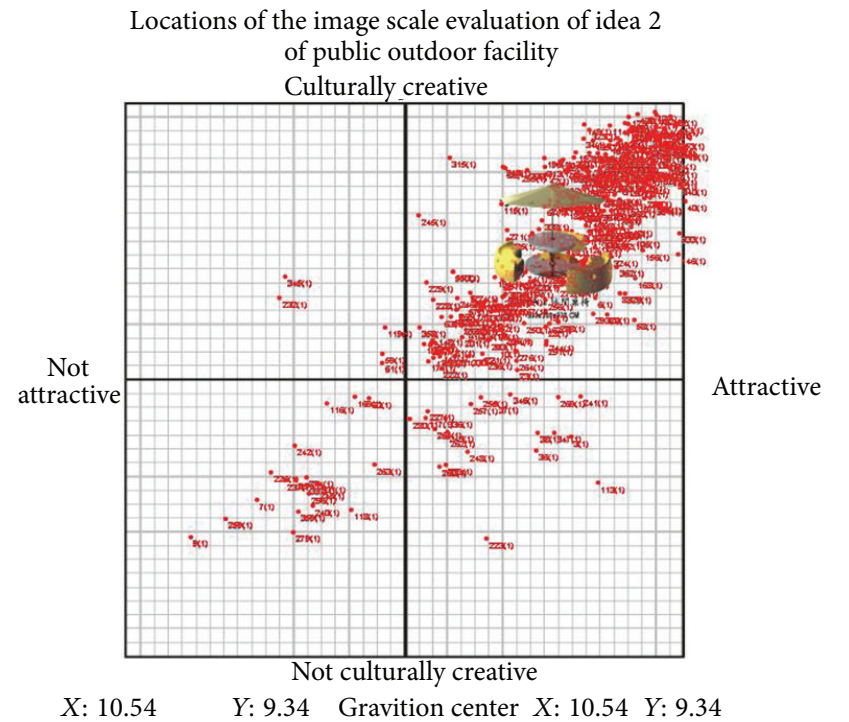

FIGURE 7: Locations of the image scale evaluation of Idea 2 of public outdoor facility.

the degrees of cultural creativity to fit in the local environment of Pearl Community.

Moreover, the marginal test of attractiveness (along $X$ axis) demonstrated that there existed significant differences among three proposals in their degrees of attractiveness $(P$ value $<0.0001<0.05)$. Furthermore, pairwise comparison and contrast test were conducted to obtain the order of design proposals. Table 3 lists the $X$ and $Y$ LSMEAN of the pairwise comparison of attractiveness of design proposals. The mark “*” means that there exists a significant difference between two ideas. For any two ideas without the mark "*”, there is no significant difference between these ideas, representing that they are similar to each other in terms of attractiveness. From Table 3, it can be seen that Idea 1 and Idea 3 are of the same cluster. Along the $Y$ axis, the marginal test of cultural creativity of design proposals of public outdoor facility also demonstrated that there existed significant differences among different proposals $(P$ value $<0.0001<0.05)$ (see Table 2). Therefore, pairwise comparison and contrast test were conducted to obtain the order of design proposals in cultural creativity. From the pairwise comparison of cultural creativity of design proposals, there were significant differences between Idea 1 and Idea 2 and between Idea 2 and
Idea 3 (groups with the mark “*”) (Table 3). Among them, Idea 2 was considered the best in terms of cultural creativity.

From the contrast test along $X$ axis (attractiveness of design proposals), there existed significant differences among design proposals $(P$ value $<0.0001<0.05)$. More importantly, Idea 2 was significantly more attractive than Ideas 1 and 3, confirming the result of pairwise comparison. Along $Y$ axis, the contrast test also demonstrated significant differences among three design proposals $(P$ value $<0.0001<0.05)$. The fact obtained from pairwise comparison that Idea 2 was significantly more creative than Ideas 1 and 3 was confirmed.

From one-way MANOVA, we could reach the conclusion that Idea 2 was better than Idea 1 and Idea 3 both in axis $X$ and axis $Y$. It was much more attractive and culturally creative. Therefore, it was the most suitable idea for new public outdoor facility in Pearl Community. Consequently, Idea 2 was used for further preference evaluation by user groups of different life styles.

3.3. Life Style Analysis. With the data of life style variables obtained from the survey, life style patterns of the target user group were analyzed by factor analysis. Through the principal component analysis, the original 15 variables were simplified into several factors. Each of these factors was independent of the others after the VariMax operation. Moreover, the newly transformed information can serve as input data for further cluster analysis from which a cross-tabulation can be synthesized.

Through reliability test, Cronbach's alpha value was $0.799>0.7$, indicating that the data were highly reliable and suitable for factor analysis. From factor analysis, the KMO (Kaiser-Meyer-Olkin) measure of sampling adequacy was 0.858 , a coefficient meritorious for factor analysis; the value of Bartlett's test of sphericity was 5524.396 with 0.000 the $P$ value, reaching the significant level. These data demonstrated that the data from life style survey were appropriate for factor analysis.

The factor extracted from principal component analysis can explain a certain part of the total variance. From the rotation sums of squared load, factor 1 could explain $32.77 \%$ of the total variance; factor 2 29.16\%; factor $319.14 \%$. In total, these three components could explain $81.07 \%$ of the total variance. The eigenvalues and cumulative percentage of components are shown in Table 4.

Through the rotated component matrix of the life style survey, the extraction, and name of the principal factors 
TABLE 4: Eigenvalues and cumulative \% of components (extraction method: principal component analysis).

\begin{tabular}{|c|c|c|c|c|c|c|c|c|c|}
\hline \multirow{2}{*}{ Component } & \multicolumn{3}{|c|}{ Initial eigenvalues } & \multicolumn{3}{|c|}{ Extraction sums of squared loadings } & \multicolumn{3}{|c|}{ Rotation sums of squared load } \\
\hline & Total & $\begin{array}{c}\% \text { of } \\
\text { Variance }\end{array}$ & $\begin{array}{c}\text { Cumulative } \\
\% \\
\end{array}$ & Total & $\begin{array}{c}\% \text { of } \\
\text { Variance }\end{array}$ & $\begin{array}{c}\text { Cumulative } \\
\% \\
\end{array}$ & Total & $\begin{array}{c}\% \text { of } \\
\text { Variance }\end{array}$ & $\begin{array}{c}\text { Cumulative } \\
\%\end{array}$ \\
\hline 1 & 5.00 & 33.30 & 33.30 & 5.00 & 33.30 & 33.30 & 4.92 & 32.77 & 32.77 \\
\hline 2 & 4.32 & 28.80 & 62.10 & 4.32 & 28.80 & 62.10 & 4.37 & 29.16 & 61.93 \\
\hline 3 & 2.85 & 18.97 & 81.07 & 2.85 & 18.97 & 81.07 & 2.87 & 19.14 & 81.07 \\
\hline
\end{tabular}

TABLE 5: Rotated component matrix of the life style survey.

\begin{tabular}{llccc}
\hline \multirow{2}{*}{ Factor } & Rotated component & \multicolumn{3}{c}{ Component } \\
& matrix & 1 & 2 & 3 \\
\hline \multirow{5}{*}{ Public } & Active in public & $\mathbf{0 . 9 1 7}$ & -0.169 & -0.098 \\
activity & welfare & & & \\
enthusiastic & Outdoor activity & $\mathbf{0 . 9 0 0}$ & -0.176 & -0.047 \\
& Segular meeting & $\mathbf{0 . 8 9 6}$ & -0.199 & -0.045 \\
& Recial anxiety & $\mathbf{0 . 8 8 5}$ & -0.170 & -0.016 \\
& Household life & $\mathbf{0 . 7 6 6}$ & 0.399 & -0.026 \\
& Picky in shopping & $\mathbf{0 . 7 0 2}$ & 0.503 & 0.156 \\
& Regular life & -0.043 & 0.192 & -0.114 \\
\hline \multirow{5}{*}{ Earnest in life } & Appearance aware & -0.066 & $\mathbf{0 . 9 3 1}$ & -0.037 \\
& Job affirmation & -0.052 & $\mathbf{0 . 9 2 1}$ & -0.095 \\
& Independent worker & -0.041 & $\mathbf{0 . 9 1 6}$ & -0.150 \\
& Political indifference & 0.367 & $\mathbf{0 . 5 6 5}$ & 0.546 \\
\hline \multirow{3}{*}{ Lohas fashion } & Leisure first & -0.048 & -0.105 & $\mathbf{0 . 9 1 9}$ \\
& Brand loyalty & -0.133 & -0.083 & $\mathbf{0 . 9 1 3}$ \\
& Fashion sensitive & -0.092 & -0.060 & $\mathbf{0 . 8 9 9}$ \\
\hline
\end{tabular}

according to the factor loadings of the questions in the major components, as can be seen in Table 5, the first factor axis is related to the way the subjects participate in public activity. It can be represented by such variables as "active in public welfare" (0.917), "outdoor activity" (0.900), "regular meeting” (0.896), and "social anxiety" (0.885). Therefore, it was defined as the "public activity enthusiastic" factor. The second axis indicates the way people look at their life and job, as expressed by such variables as "regular life" (0.949), "appearance aware" (0.931), "job affirmation" (0.921), and "independent worker" (0.916). For this reason, it is defined as the "earnest in life" factor. The third axis is related to the way people feel about leisure and fashion and can be defined as the "Lohas fashion" factor. Typical image words such as "leisure first" (0.919), "brand loyalty" (0.913), and "fashion sensitive" (0.899) can be used to represent this factor. These three factor axes represent the main criteria of target users in life style. To explore the differentiation of consumers in life style, the regression factor scores obtained from factor analysis were used for a cluster analysis. In the analysis, the number of clusters was chosen based on the cubic clustering criterion (CCC), and it is clear that the classification of four clusters has the highest value $(\mathrm{CCC}=69.042)$. Therefore, the subjects were divided into four groups in terms of their attitudes in life style.
To check the stability of life style clusters, a one-way MANOVA was conducted. The function can be represented as $[Y 1, Y 2, Y 3]=f(A)$, where $Y 1=$ public activity enthusiastic factor; $Y 2$ = earnest in life factor; $Y 3=$ Lohas fashion factor; $A=$ type of life style group, $A=1-4$. The MANOVA summary of the life style clusters is shown in Table 6. The $P$ value of Wilks' Lambda test $<0.0001$ indicates there are significant differences among four life style groups in terms of three major component factors. Therefore, these life style groups were further categorized and named in accordance with the life style factors.

For the marginal test of public activity enthusiastic factor, the $P$ value $<0.0001$, meaning that there were significant differences among different life style groups. Furthermore, the pairwise comparison and contrast test show the order of these life style groups in terms of public activity enthusiastic factor. The pairwise comparison of four life style groups in Factor 1 LSMEAN is shown in Table 7. It can be seen that each life style group was significantly different from other groups with life style Group 4 being the highest (1.579 in Factor 1). Similarly, the $P$ value of the marginal test of earnest in life factor was less than 0.0001 , indicating that there were significant differences among different life style groups. The order of these life style groups in terms of earnest in life factor can be illustrated from the pairwise comparison and contrast test. The pairwise comparison of four life style groups in Factor 2 LSMEAN indicated that there was a significant difference between each two life style groups except between Group 2 and Group 4. Therefore, in terms of the earnestness in life, life style Groups 2 and 4 could be defined as the same cluster; Groups 1 and 3 belonged to the other two groups. Life style Group 3 had the highest degree of earnestness in life (1.693). In terms of the marginal test on Lohas fashion factor, $P$ value $<0.0001$, indicating that there were significant differences among different life style groups. Moreover, the pairwise comparison of four life style groups in Factor 3 LSMEAN showed that there was a significant difference between each two life style groups except between Group 3 and Group 4. Among four life style groups, Group 2 had the highest score (1.507). Through the hypotheses test, there are significant differences among four life style groups in terms of life style factors. Results of the test of hypotheses are shown in Table 7.

Based on the significant differences and the order of the life style groups along three major life style factors, typical groups were selected for different factors. In terms of the public activity enthusiastic factor, life style Group 4 was significantly higher than the other three groups. Therefore, 
TABLE 6: Tests of hypotheses for life style factors.

\begin{tabular}{|c|c|c|c|}
\hline Items of tests & Research hypotheses & $P$ value & Test result \\
\hline Total test & $\mathrm{H}_{1}$ : the model is significant & $<.0001^{*}$ & Significant \\
\hline $\begin{array}{l}\text { Marginal test of public } \\
\text { activity enthusiastic }\end{array}$ & $\begin{array}{l}\mathrm{H}_{1}: \text { the model of public activity } \\
\text { enthusiastic is significant. }\end{array}$ & $<.0001^{*}$ & Significant \\
\hline $\begin{array}{l}\text { Paired test of public activity } \\
\text { enthusiastic }\end{array}$ & $\begin{array}{l}\mathrm{H}_{1} \text { : there exist significant differences in } \\
\text { public activity enthusiastic between } \\
\text { every two groups in the target market. }\end{array}$ & & See Table 7 \\
\hline $\begin{array}{l}\text { Contrast test of public } \\
\text { activity enthusiastic }\end{array}$ & $\begin{array}{l}\mathrm{H}_{1} \text { : there exist significant differences in } \\
\text { public activity enthusiastic between } \\
\text { life style groups. }\end{array}$ & $<.0001^{*}$ & Significant \\
\hline $\begin{array}{l}\text { Marginal test of earnest in } \\
\text { life }\end{array}$ & $\begin{array}{l}\mathrm{H}_{1} \text { : the model of earnest in life is } \\
\text { significant. }\end{array}$ & $<.0001^{*}$ & Significant \\
\hline Paired test of earnest in life & $\begin{array}{l}\mathrm{H}_{1} \text { : there exist significant differences in } \\
\text { earnest in life between every two } \\
\text { groups in the target market. }\end{array}$ & & See Table 7 \\
\hline $\begin{array}{l}\text { Contrast test of earnest in } \\
\text { life }\end{array}$ & $\begin{array}{l}\mathrm{H}_{1} \text { : there exist significant differences in } \\
\text { earnest in life between life style groups. }\end{array}$ & $<.0001^{*}$ & Significant \\
\hline $\begin{array}{l}\text { Marginal test of Lohas } \\
\text { fashion }\end{array}$ & $\begin{array}{l}\mathrm{H}_{1} \text { : the model of Lohas fashion is } \\
\text { significant. }\end{array}$ & $<.0001^{*}$ & Significant \\
\hline Paired test of Lohas fashion & $\begin{array}{l}\mathrm{H}_{1} \text { : there exist significant differences in } \\
\text { Lohas fashion between every two } \\
\text { groups in the target market. }\end{array}$ & & See Table 7 \\
\hline $\begin{array}{l}\text { Contrast test of Lohas } \\
\text { fashion }\end{array}$ & $\begin{array}{l}\mathrm{H}_{1} \text { : there exist significant differences in } \\
\text { Lohas fashion between life style } \\
\text { groups. }\end{array}$ & $<.0001^{*}$ & Significant \\
\hline
\end{tabular}

TABLE 7: Pairwise comparison of four life style groups in public activity enthusiastic factor.

\begin{tabular}{|c|c|c|c|c|c|c|}
\hline LS group & Factor 1 LSMEAN & Group & 1 & 2 & 3 & 4 \\
\hline 1 & -.948 & 1 & & $<.0001$ & $<.0001$ & $<.0001$ \\
\hline 2 & -.542 & 2 & $<.0001^{*}$ & & $<.0001$ & $<.0001$ \\
\hline 3 & -.180 & 3 & $<.0001^{*}$ & $<.0001^{*}$ & & $<.0001$ \\
\hline 4 & 1.579 & 4 & $<.0001^{*}$ & $<.0001^{*}$ & $<.0001^{*}$ & \\
\hline LS group & Factor 2 LSMEAN & Group & 1 & 2 & 3 & 4 \\
\hline 1 & -.814 & 1 & & $<.0001$ & $<.0001$ & $<.0001$ \\
\hline 2 & -.384 & 2 & $<.0001^{*}$ & & $<.0001$ & .1272 \\
\hline 3 & 1.693 & 3 & $<.0001^{*}$ & $<.0001^{*}$ & & $<.0001$ \\
\hline 4 & -.434 & 4 & $<.0001^{*}$ & .1272 & $<.0001^{*}$ & \\
\hline LS group & Factor 3 LSMEAN & Group & 1 & 2 & 3 & 4 \\
\hline 1 & -1.058 & 1 & & $<.0001$ & $<.0001$ & $<.0001$ \\
\hline 2 & 1.507 & 2 & $<.0001^{*}$ & & $<.0001$ & $<.0001$ \\
\hline 3 & -.207 & 3 & $<.0001^{*}$ & $<.0001^{*}$ & & .791 \\
\hline 4 & -.192 & 4 & $<.0001^{*}$ & $<.0001^{*}$ & .791 & \\
\hline
\end{tabular}

it was selected as the representative group that was enthusiastic in public activities. For the earnestness in life factor, similarly, life style Group 3 was the typical group in that it was significantly higher than the other three groups along this factor. Finally, life style Group 2 was typical in Lohas fashion for the same reason.

Through grouping and differentiation along axes in MANOVA, features of different life style groups could be identified. Furthermore, the titles for life style groups were specified according to these features. In these four groups,
Group 2 could be defined as Lohas fashion group; Group 3 earnest in life group; and Group 4 public activity enthusiastic group because each of them stood out along one specific life style component factor. Finally, Group 1 was named the ordinary life group because it had the lowest factor scores along three factors. The coding of life style groups can be integrated for the options of lifestyle group in the interface of choose and calculate the group center (Figure 6) for the output of target user group preference analysis. Figure 8 illustrates the idea screening result of Group 4 public activity enthusiastic group, 
TABLE 8: Tests of hypotheses for life style groups in design proposal 2 evaluation $(X$ axis $=$ attractiveness; $Y$ axis $=$ culturally creative $)$.

\begin{tabular}{|c|c|c|c|}
\hline Items of tests & Research hypotheses & $P$ value & Test result \\
\hline Total test & $\mathrm{H}_{1}$ : the model is significant & $.0001^{*}$ & Significant \\
\hline Marginal test of $X$ axis & $\begin{array}{l}\mathrm{H}_{1} \text { : the model of different } \\
\text { attractiveness evaluations is significant. }\end{array}$ & $<.0001^{*}$ & Significant \\
\hline Pairwise comparison of $X$ axis & $\begin{array}{l}\mathrm{H}_{1} \text { : there exist significant differences in } \\
\text { attractiveness evaluation between } \\
\text { every two life style groups. }\end{array}$ & & See Table 9 \\
\hline Contrast test of $X$ axis & $\begin{array}{l}\mathrm{H}_{1} \text { : there exist significant differences in } \\
\text { attractiveness evaluation among life } \\
\text { style groups. }\end{array}$ & $<.0001^{*}$ & Significant \\
\hline Marginal test of $Y$ axis & $\begin{array}{l}\mathrm{H}_{1}: \text { the model of different cultural } \\
\text { creativity evaluations is significant. }\end{array}$ & $.0003^{*}$ & Significant \\
\hline Pair-wise comparison of $Y$ axis & $\begin{array}{l}\mathrm{H}_{1} \text { : there exist significant differences in } \\
\text { cultural creativity evaluation between } \\
\text { every two life style groups. }\end{array}$ & & See Table 9 \\
\hline Contrast test of $Y$ axis & $\begin{array}{l}\mathrm{H}_{1} \text { : there exist significant differences in } \\
\text { cultural creativity evaluation among } \\
\text { life style groups. }\end{array}$ & $<.0001^{*}$ & Significant \\
\hline
\end{tabular}

TABLE 9: The pairwise comparison of four life style groups in attractive image evaluation of design proposal 2.

\begin{tabular}{lccccc}
\hline LS GROUP & X LSMEAN & Group & 1 & 2 & 3 \\
\hline 1 & 7.64 & 1 & & $<.0001$ & .0036 \\
2 & 11.86 & 2 & $<.0001^{*}$ & .1680 & .0001 \\
3 & 10.48 & 3 & $.0036^{*}$ & .1680 & .7650 \\
4 & 12.15 & 4 & $<.0001^{*}$ & .7650 & .0773 \\
\hline LS GROUP & Y LSMEAN & Group & 1 & .0773 & 3 \\
\hline 1 & 6.72 & 2 & $.0010^{*}$ & .0082 & .4769 \\
2 & 10.25 & 3 & $.0082^{*}$ & .4769 & .5583 \\
3 & 9.48 & 4 & .5583 & .1759 \\
4 & 10.85 & $<.0001^{*}$ & .1759 \\
\hline
\end{tabular}

in which Idea 2 had the highest coordinates $(12.15,10.85)$, indicating that Idea 2 was the most favored proposal for Group 4.

3.4. Promotional Strategy for the Product Ideas. In this study, the coordinates of design proposal 2 along attractiveness and cultural creativity axes and life style groups were used for oneway MANOVA. From this, differences among life style groups were specified to explore the profile of target user group for the design proposal of public outdoor facility. Such kind of data could serve as references for promotion of cultural creativity in public outdoor facility design in the neighborhood.

The MANOVA summary of the life style groups along $X$ axis of attractiveness and $Y$ axis of cultural creativity is shown in Table 8 . The $P$ value of Wilks' Lambda test was $0.0001<0.05$, indicating there were significant differences among four life style groups in terms of the evaluation of design proposal 2. Therefore, details of the differences regarding design proposal 2 were further examined. Details for the pairwise comparison and contrast test are shown in Table 9.

For the evaluation of attractiveness of design proposal 2 , the marginal test showed significant differences in four life style groups $(P$ value $<0.0001<0.05)$. Moreover, the pairwise comparison of four life style groups in attractive image evaluation of design proposal 2 (Table 9) showed that life style group 1 was significantly different from the other three groups. However, there was no significant difference between any two groups among Groups 2, 3, and 4. Among them, life style Group 4 was of the highest LSMEAN value (12.15). In cultural creativity evaluation of design proposal 2, the marginal test showed significant differences in four life style groups $(P$ value $=0.0003<0.05)$. Moreover, the pairwise comparison of four life style groups in cultural creativity evaluation of design proposal 2 showed that life style group 1 was significantly different from the other three groups. Similar to the evaluation of attractiveness for design proposal 2 , there was no significant difference between any two groups among Groups 2, 3, and 4. Among them, life style Group 4 was of the highest LSMEAN value (10.85).

The results of contrast test along $X$ (attractiveness) and $Y$ (cultural creativity) axes indicated that there existed significant differences in four life style groups in looking at design proposal 2. Members in Groups 2, 3, and 4 considered design proposal 2 more attractive than did members in group $1(P$ value $>0.0001)$. In other words, life style Groups 2, 3, and 4 


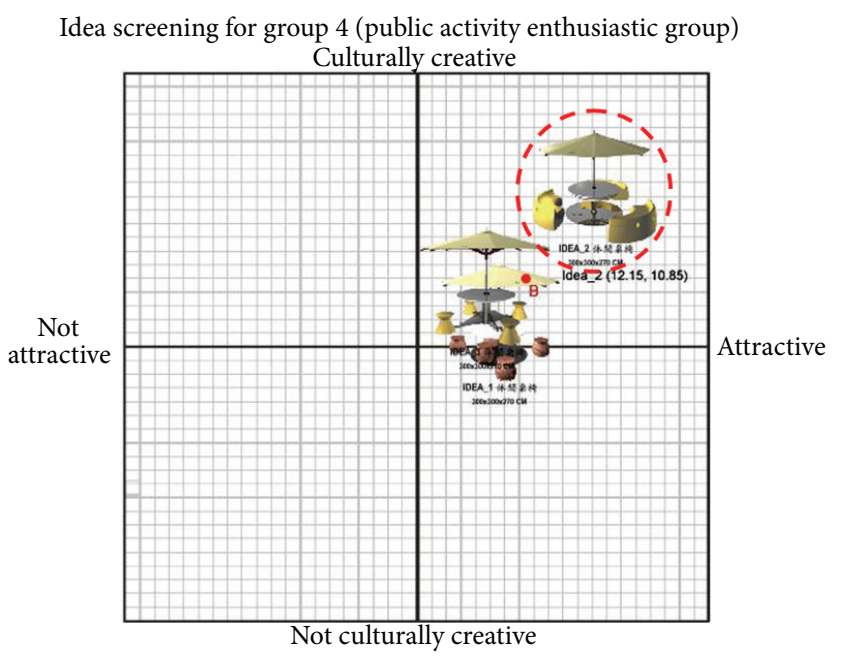

$X: 12.15 \quad Y: 10.85$

FIGURE 8: Idea screening for Group 4 (public activity enthusiastic group).

could be seen as target user groups that prefer design proposal 2 of the public outdoor facility for Pearl Community. For cultural creativity evaluation of design proposal 2 , the result was similar. Subjects in Group 1 thought design proposal 2 is not so creative for the straw image as did the subjects in life style Groups 2, 3, and 4. Therefore, Groups 4, 2, and 3 can be seen as the target user groups that prefer design proposal 2.

Because characteristics of different life style groups may acquire different promotional strategies, for design proposal 2 of public outdoor facility, life style Groups 4, 2, and 3 could be considered the same category in that there was no significant difference on $X$ and $Y$ axes. This also means that design proposal 2 can be accepted by the majority of people. In the promotional strategy, life style Group 4 (the public activity enthusiastic group) could be chosen as the target user group for design proposal 2 because its LSMEAN values for design proposal 2 on both $X$ and $Y$ axes were higher than those of other groups. Particularly, subjects of this group liked to participate in public welfare activity, go shopping, watch movies and exhibitions, and do the like outdoor activities. People with such features are potential users for the public outdoor facility. Therefore, it is suggested that Pearl Community invites tourists to join their public welfare activity. Design proposal 2 can be placed in a film or advertising flyer to promote public outdoor facilities in similar communities. Figure 9 illustrates the scaled model of design proposal 2, which was displayed in the community for further promotional concern.

\section{Conclusions}

The web-based tool was used for the idea screening and life style survey of public outdoor facility design in Pearl Community in Yi-Lan County, Taiwan. The data collected were analyzed to draft the promotional strategy for specific target user groups.

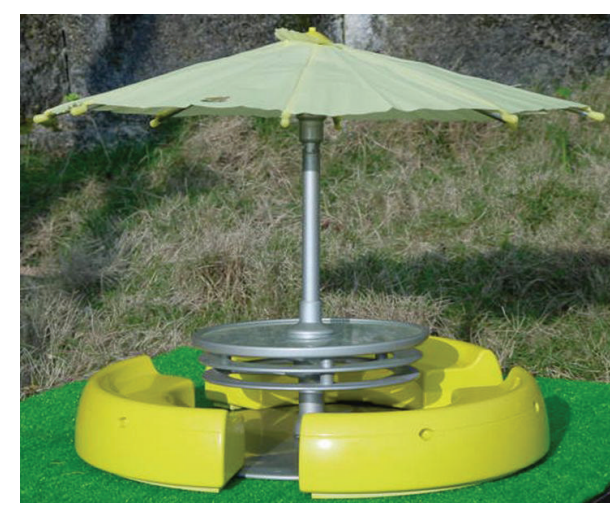

Figure 9: The scaled model for design Idea 2 of public outdoor facility.

Results of the study demonstrated that through the interactive web page design, life style questionnaire could be combined with the web-based tool. For subjects, the interface design for the survey was acceptable. Moreover, it is more effective for subjects to locate the product image samples through multiple dynamic views. Compared with single perspective views used in common systems, multiple dynamic views give subjects more details and lively images regarding the design proposals. The offering of detailed product from features makes it easier for the subjects to conduct their image and preference evaluations.

Concrete contributions of this study made to the practical design field are listed below.

(1) Through the calculation of gravitation centers in frequently used image scale in design industry, the subjective viewpoints of smaller sampling size can be turned into objective coordinate data of a much bigger number of consumers through the website.

(2) In addition to the demographic analyses, the analytical analyses had integrated the life style questionnaire from which the degrees of preferences for design ideas can be further specified for special target user groups, serving as a reference for product promotion policy.

(3) The project setting and product sample upload are no longer limited to time and space. After the survey, designers or researchers can choose to prompt the output diagrams for specific target user groups, including special demographic and life style user groups in terms of the preferences towards product proposals. Furthermore, quantitative analyses regarding the potential target user groups can be conducted based on the coordinate data of the product ideas, making it possible for designers or researchers to gather objective data about the customers' voices from the market.

(4) The statistical analysis of the design proposal locations and life style variables can help define the target user group and work out a proper promotion strategy for product design. In the form of clear 
output diagrams and quantitative data, the webbased tool can offer feedbacks to designers for their design proposals. These data can serve as guidelines for objective idea screening. The extension of life style study from the web-based tool offers a feasible platform for designers to process their product design and promotion.

Due to the limits of manpower and time, only the public outdoor facility design project was explored in this study. From the survey of the web-based tool, it is essential to ensure that the subjects know how to process the evaluation. Especially, a tutorial for the novice users is necessary. Eventually, many details such as the functions for complicated products should be clearly presented by multiple $2 \mathrm{D}$ or $3 \mathrm{D}$ views. An in-depth study of the user interface or other types of products for such an analytical system is required. The web-based tool proposed in this study was installed on a fixed IP address in the laboratory. Currently, such kind of survey should be done in the laboratory in which the images and questions in the questionnaire should be submitted and downloaded in the system. Such a limitation can be overcome by ASP program from which the customer's computer can be linked to the server for the retrieval of database and the filling in of the questionnaire. Moreover, multiple images were prompted in the current system. In the future, the incorporation of audio and video programs will make it possible for us to download video files such as CF (commercial film) advertising for the marketing research. Finally, more detailed consumer behaviors can be investigated through the combination of the web-based tool and eye tracking system from which more data regarding product feature and user interface design can be offered for designers and engineers.

\section{Conflict of Interests}

The author declares that there is no conflict of interests regarding the publication of this paper.

\section{Acknowledgments}

The web-based tool had been granted the patent of invention by Bureau of Patent, Taiwan, ROC (two Patents nos. I 228669 and I 321758). It won the silver medal for software invention in INEA Germany 2007 and the gold medal for software invention in Geneva Swiss 2010.

\section{References}

[1] M. Baxter, Product Design: A Practical Guide to Systematic Methods of New Product Development, Chapman \& Hall, London, UK, 1995.

[2] S. H. Hsu, M. C. Chuang, and C. C. Chang, "A semantic differential study of designers' and users' product form perception," International Journal of Industrial Ergonomics, vol. 25, no. 4, pp. 375-391, 2000.

[3] M. Ikudame and A. Harada, "The tool for measurement of visual image," Bulletin of JSSD, p. 114, 1997.

[4] C. S. Tu, "The development of the web-based global interactive MDS questionnaire survey," Journal of Design, vol. 2, no. 1, pp. $1-15,1997$.
[5] M. Nagamachi, "Kansei engineering: a new ergonomic consumer-oriented technology for product development," International Journal of Industrial Ergonomics, vol. 15, no. 1, pp. 3-11, 1995.

[6] M. C. Chuang and C. H. Kao, "A study on the image of products made in Taiwan," Journal of Design, vol. 2, no. 2, p. 37, 1997.

[7] M. C. Chuang, C. C. Chang, and S. H. Hsu, "Perceptual factors underlying user preferences toward product form of mobile phones," International Journal of Industrial Ergonomics, vol. 27, no. 4, pp. 247-258, 2001.

[8] M.-C. Chuang and Y.-C. Ma, "Expressing the expected product images in product design of micro-electronic products," International Journal of Industrial Ergonomics, vol. 27, no. 4, pp. 233245, 2001.

[9] H. C. Chang, H. H. Lai, and Y. M. Chang, "Expression modes used by consumers in conveying desire for product form: a case study of a car," International Journal of Industrial Ergonomics, vol. 36, no. 1, pp. 3-10, 2006.

[10] C. E. Osgood, C. J. Suci, and P. H. Tannenbaum, The Measurement of Meaning, University of Illinois Press, Urbana, Ill, USA, 1957.

[11] K. Shigenobu, Color Image Scale, Kodansha International, Tokyo, Japan, 1991.

[12] U. Roy and S. S. Kodkani, "Collaborative product conceptualization tool using Web technology," Computers in Industry, vol. 41, no. 2, pp. 195-209, 2000.

[13] G. Q. Huang, S. W. Lee, and K. L. Mark, Web-Based Product and Process Data Modeling in Concurrent Design for X, Department of Industrial and Manufacturing Systems Engineering, The University of Hong Kong, Pokfulam Road, Hong Kong, 1999.

[14] E. B. Taylor, Primitive Culture, J. Murray, London, UK, 1871.

[15] R. W. Wuthnow, J. D. Hunter, and A. Bergesen, Culture Analysis, Routledge, New York, NY, USA, 1991.

[16] D. Leong and H. Clark, "Culture-based knowledge towards new design thinking and practice-a dialogue," Design Issues, vol. 19, no. 3, pp. 48-58, 2003.

[17] R. T. Lin, "Creative learning model for cross cultural product," Art Appreciation, vol. 1, no. 12, pp. 52-59, 2005.

[18] W. Lazer, "Life style concepts and marketing," in Toward Scientific Marketing, S. Greyser, Ed., pp. 196-197, AMA, Chicago, Ill, USA, 1963.

[19] B. Berman and J. R. Evans, Marketing, Macmillan, 1982.

[20] J. F. Engel, D. T. Kollat, and R. D. Blackwell, Consumer Behavior, The Dryden Press, Chicago, Ill, USA, 1993.

[21] W. D. Wells and D. J. Tigert, "Activities, interests and opinions," Journal of Advertising Research, vol. 11, pp. 27-35, 1971.

[22] J. T. Plummer, "The concept and application of life-style segmentation," Journal of Marketing, vol. 38, no. 1, p. 33, 1974.

[23] S. Y. Huang and J. S. Lin, “Analyzing target user group's preferences and product form design specification through web-based 2-dimensinoal design decision tool," International Journal of Business Research and Management, vol. 1, no. 2, pp. 14-32, 2010. 


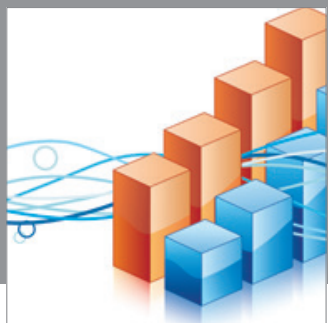

Advances in

Operations Research

mansans

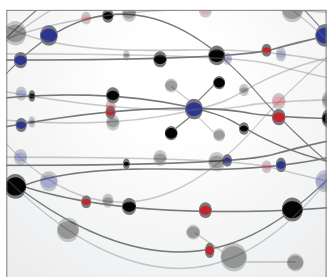

The Scientific World Journal
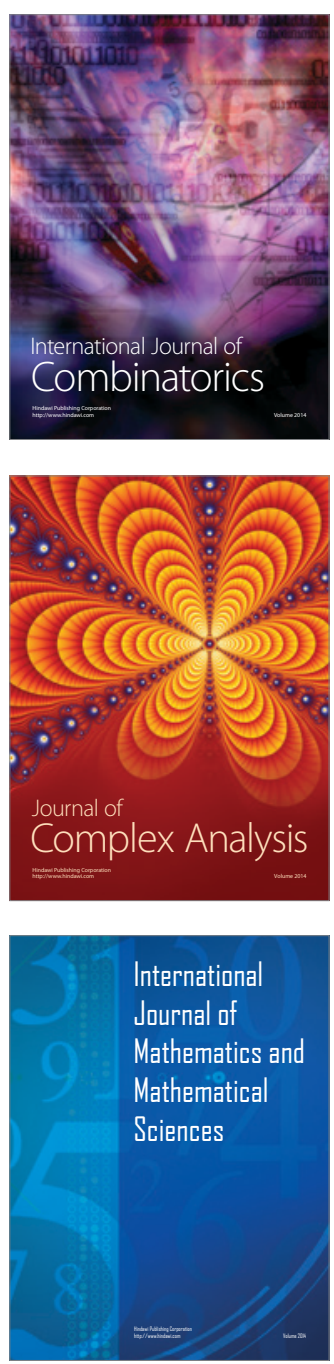
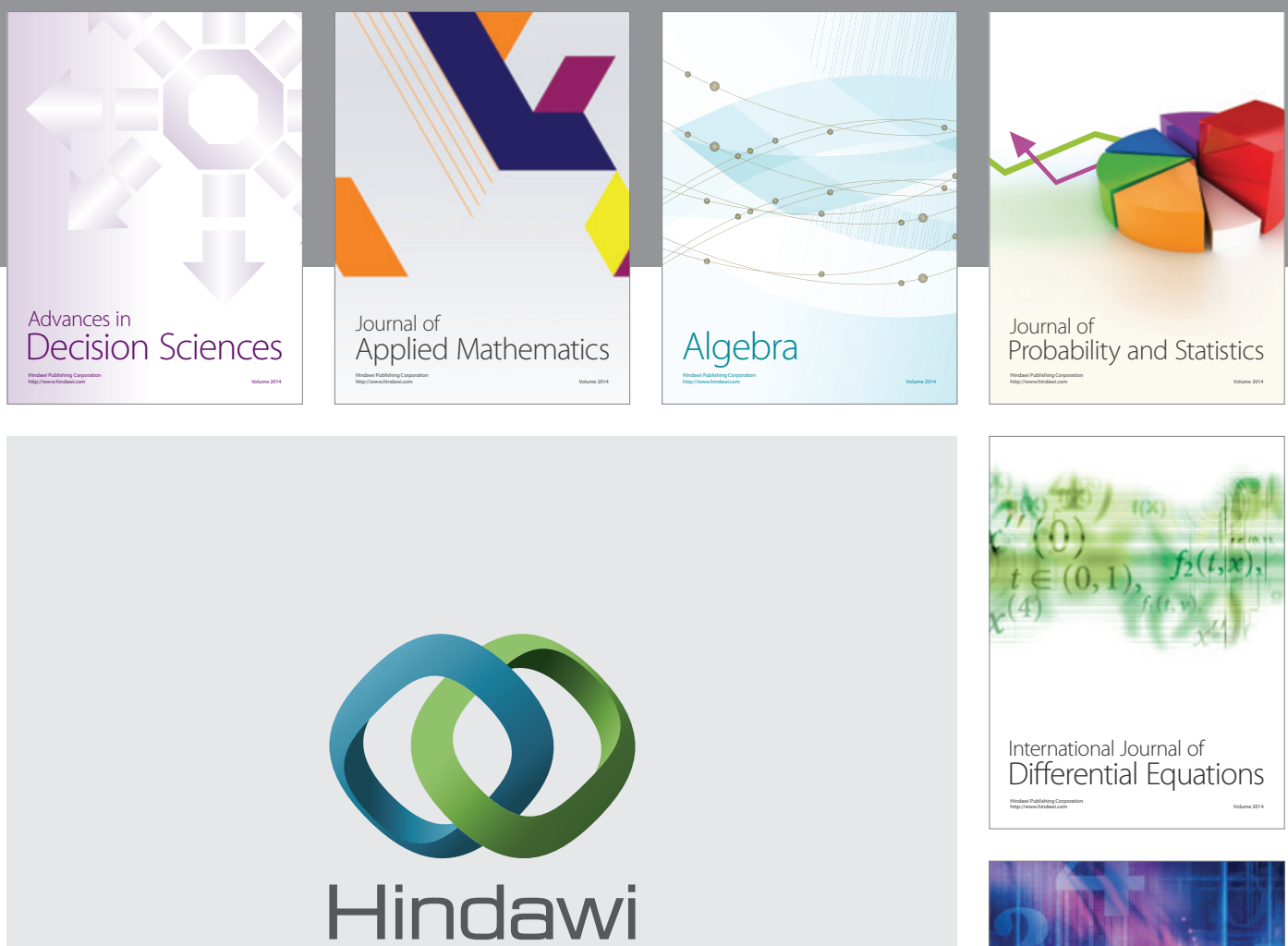

Submit your manuscripts at http://www.hindawi.com
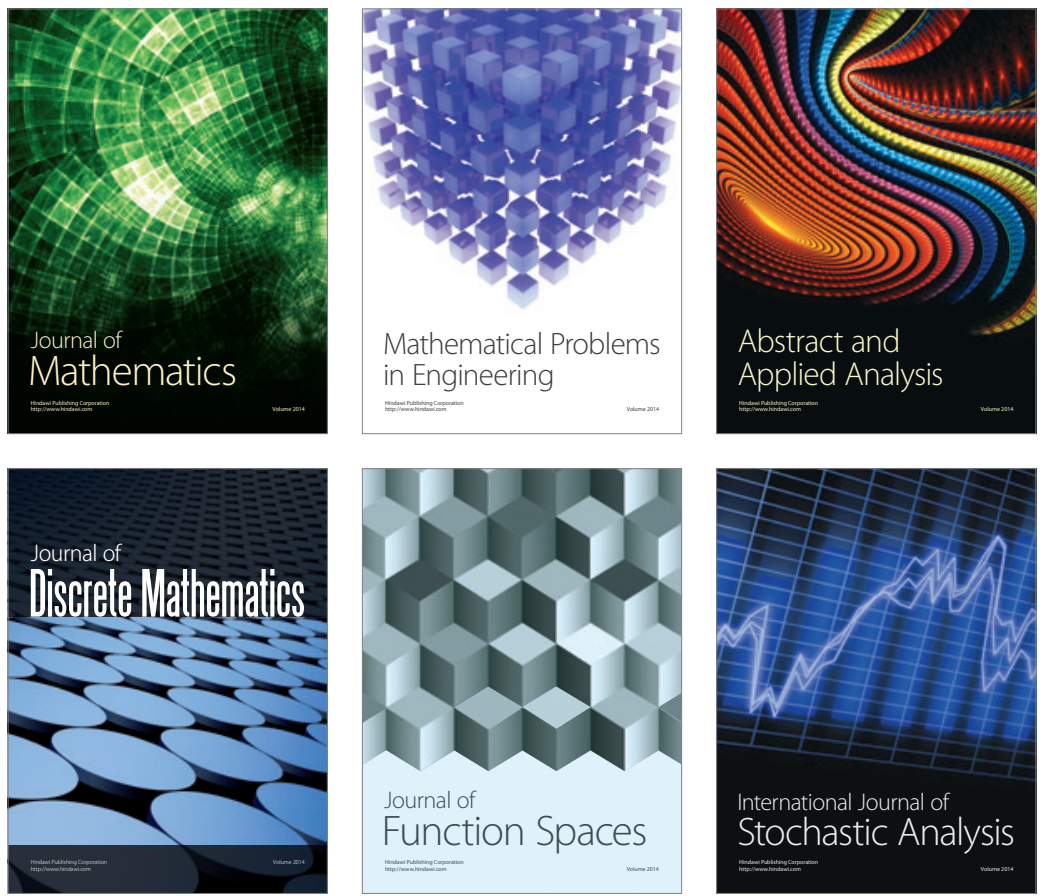

Journal of

Function Spaces

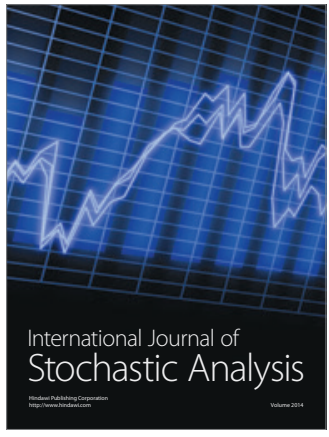

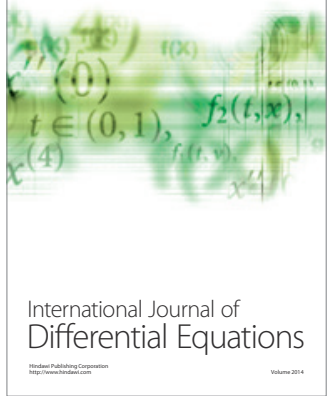
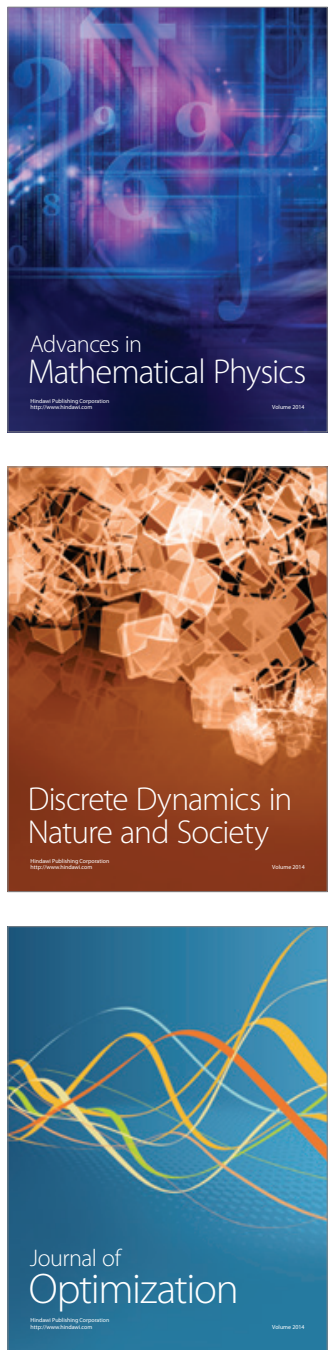